\title{
Bifractionated CPT-11 with LV5FU2 infusion (FOLFIRI-3) in combination with bevacizumab: clinical outcomes in first-line metastatic colorectal cancers according to plasma angiopoietin-2 levels
}

Stefano Kim¹, Erion Dobi ${ }^{1}$, Marine Jary ${ }^{1}$, Franck Monnien ${ }^{1}$, Elsa Curtit ${ }^{1}$, Thierry NGuyen', Zaher Lakkis², Bruno Heyd ${ }^{2}$, Serge Fratte ${ }^{3}$, Denis Cléau ${ }^{4}$, Najib Lamfichekh ${ }^{5}$, Virginie Nerich ${ }^{7}$, Boris Guiu ${ }^{6}$, Martin Demarchi ${ }^{1}$ and Christophe Borg ${ }^{1,8,9^{*}}$

\begin{abstract}
Background: Optimization of chemotherapy effectiveness in metastatic colorectal cancers (mCRC) is a major endpoint to enhance the possibility of curative intent surgery. FOLFIRI3 has shown promising results as second-line chemotherapy for mCRC patients previously exposed to oxaliplatin. The clinical efficacy of FOLFIRI3 was never determined in association with bevacizumab in non-previously treated mCRC patients.

Methods: We conducted a phase II clinical trial to characterize the response rate and toxicity profile of FOLFIRI3-bevacizumab as initial treatment for mCRC. Sixty-one patients enrolled in 3 investigation centers were treated with FOLFIRI3-bevacizumab (median of 10 cycles) followed by a maintenance therapy combining bevacizumab and capecitabine. Levels of plasma angiopoietin-2 (Ang-2) were measured by enzyme-linked immunosorbent assay at baseline.
\end{abstract}

Results: Overall response rate (ORR) was $66.7 \%$ ( $8 \%$ of complete and $58 \%$ of partial responses). The disease control rate was $91.7 \%$. After a median time of follow-up of 46.7 months, 56 patients (92\%) had progressed or died. The median progression free survival (PFS) was 12.7 months (95\% confidence interval (CI) 9.7-15.8 months). The median overall survival (OS) was 24.5 months (95\% Cl: 10.6-38.3 months). Twenty-one patients underwent curative intent-surgery including 4 patients with disease initially classified as unresectable. Most common grade III-IV toxicities were diarrhea (15\%), neutropenia (13\%), asthenia (10\%), and infections (4\%). Hypertension-related medications needed to be increased in 3 patients. In multivariate analysis, surgery of metastases and Ang-2 levels were the only independent prognostic factors for PFS and OS. Indeed, baseline level of Ang-2 above $5 \mathrm{ng} / \mathrm{mL}$ was confirmed as an independent prognostic factor for progression free survival ( $H R=0.357 ; 95 \% \mathrm{Cl}: 0.168-0.76, p=0.005)$ and overall survival ( $\mathrm{HR}=0.226 ; 95 \% \mathrm{Cl}: 0.098-0.53, \mathrm{p}=0.0002)$.

Conclusions: As front-line therapy, FOLFIRI-3-bevacizumab is associated with an acceptable toxicity and induced promising objective response rates. However, unfavorable clinical outcomes were observed in patients with high levels of angiopoietin-2.

Keywords: Colorectal cancer, Bevacizumab, FOLFIRI3, Irinotecan, Angiopoietin-2

\footnotetext{
* Correspondence: christophe.borg@efs.sante.fr

'Department of medical oncology, University Hospital of Besançon, Besançon, France

${ }^{8}$ INSERM, University of Franche-Comté, Unit 1098, Besançon, France

Full list of author information is available at the end of the article
} 


\section{Background}

Recent advances in surgery of metastases, as well as the widespread use of adjuvant chemotherapy, improved the outcomes of colorectal cancer patients [1-3]. For patients diagnosed with metastatic disease or relapsing after oxaliplatin-based adjuvant therapy, optimization of chemotherapy effectiveness is a major endpoint to enhance the possibility of curative intent surgery. For those patients, CPT-11 (irinotecan)-containing chemotherapies are an available option, particularly when combined with biotherapies.

Irinotecan, a campthotecin analogue, inactivates topoisomerase I via its active metabolite SN38. In first-line $\mathrm{mCRC}$ patients, the addition of irinotecan $\left(180 \mathrm{mg} / \mathrm{m}^{2}\right)$ to LV5FU2 (FOLFIRI) conferred a significant survival advantage over LV5FU2 alone (leucovorin (LV) $200 \mathrm{mg} / \mathrm{m}^{2}$ day 1, 5-fluorouracil (5FU) bolus $400 \mathrm{mg} / \mathrm{m}^{2}$ day 1 followed by a 46 hours-5FU continuous infusion $2400 \mathrm{mg} / \mathrm{m}^{2}$ ) [4]. Similarly, the addition of irinotecan to bolus of fluorouracil resulted in longer overall survival compared to fluorouracil alone [5]. The clinical benefit of irinotecan was also demonstrated in patients whose disease had progressed after first-line 5FU [6,7].

Irinotecan, administered alone or in combination with LV5FU2 (FOLFIRI), is also a recommended therapy for second-line metastatic diseases in patients previously exposed to oxaliplatin. In this setting, irinotecan as single agent or in combination with LV5FU2 induces a $4 \%$ objective response rate and a progression free survival of 2.5 months $[8,9]$. These results prompted many investigators to examine new approaches to optimize irinotecan-based chemotherapies.

Bifractionated CPT-11 with LV5FU2 (FOLFIRI3) was identified as an effective therapy in patients previously exposed to oxaliplatin-containing chemotherapies [10-12]. In FOLFIRI3 regimen, $100 \mathrm{mg} / \mathrm{m}^{2}$ of irinotecan are delivered as a 60 minutes infusion before and at the end of LV5FU2. In a phase II trial, FOLFIRI3 regimen was assessed in patients previously treated with FOLFOX and achieved an objective response rate of $23 \%$. Furthermore, a stable disease was observed in $37 \%$ of the patients and the progression free survival was 4.2 months [10]. Bidard FC et al. analyzed the clinical interest of several irinotecanbased protocols delivered in the second-line setting for patients previously included in the OPTIMOX 1 study. These patients were treated by FOLFOX in the first-line setting and were prospectively registered for subsequent treatments. FOLFIRI3 chemotherapy was associated with a significantly better objective tumor response rate (17\% compared to $8 \%$ with FOLFIRI) and an enhanced progression free survival (3.7 months compared to 3 months with FOLFIRI) [11]. These results suggested that bi-fractionated irinotecan might be a relevant option for patients previously treated with oxaliplatin.
Then, this phase II clinical trial was designed to assess the clinical efficacy and toxicity of FOLFIRI3 in combination with bevacizumab (FOLFIRI3-b), a Vascular Endothelial Growth Factor-neutralizing monoclonal antibody indicated for the first-line treatment of metastatic CRC patients [13].

Although there are currently no biomarkers with proven clinical interest to identify patients eligible to bevacizumab and chemotherapy, a pilot study performed on 34 metastatic colorectal cancer patients treated with chemotherapy and bevacizumab showed that high levels of plasma angiopoietin-2 predict a poor prognosis [14]. Therefore, we decided to perform an ancillary study to further substantiate the prognostic value of baseline angiopoietin-2 plasma levels in patients treated with FOLFIRI3 and bevacizumab.

\section{Methods}

\section{Study design}

The main objective of this single-arm phase II study was to determine the objective response rate of FOLFIRI3-b for patients undergoing first-line treatment of metastatic colorectal cancer. Secondary objectives were the monitoring of side effects, the assessment of median progression free and overall survival and the characterization of angiopoietin-2 prognostic value. Sixty-one patients were enrolled in two general hospitals and a university hospital. The study was conducted in accordance with the Declaration of Helsinki, the International Conference on Harmonization Guidelines for Good Clinical Practice. Each patient gave written consent before entering the study. The protocol was approved by the ethical committee CPP Est-II and registered on ClinicalTrials.gov (study NCT00544011).

\section{Eligibility}

Patients with first-line $\mathrm{mCRC}$ and measurable lesions were included. Previous adjuvant chemotherapy was allowed provided that the last administration was given at least 6 months before randomization. Other eligibility criteria were: age 18 to 80 years, Eastern Cooperative Oncology Group Performance Status 0, 1 or 2 and written informed consent. Exclusion criteria included: previous bevacizumab treatment; proteinuria exceeding $1 \mathrm{~g} / 24 \mathrm{~h}$; coagulopathy; inadequate hematologic function (absolute neutrophil count $<1.0 \times 10^{9} / \mathrm{L}$, platelets $\left.<100 \times 10^{9} / \mathrm{L}\right)$; inadequate hepatic function (total bilirubin $>1.5 \times$ upper limit of normal (ULN), serum transaminases $>2 \times$ ULN in absence of liver metastases or $>5 \times$ ULN in presence of liver metastases); inadequate renal function (clearance of creatinine $<30 \mathrm{ml} / \mathrm{min}$ ); major surgery $<28$ days before inclusion; non-controlled cardiovascular disease; non-controlled hypertension; active hemorrhagic event; aspirin more than $325 \mathrm{mg} /$ day treatment. As the main 
objective was to assess the tumor response rate, patients amenable to curative intent surgery were included in the study. Surgery of metastases was allowed after 6 cycles of FOLFIRI3-b and the precise timing left at the discretion of investigators.

\section{Treatment}

FOLFIRI3-bevacizumab regimen consisted of bevacizu$\mathrm{mab} 5 \mathrm{mg} / \mathrm{kg}$ day 1 , irinotecan $100 \mathrm{mg} / \mathrm{m}^{2}$ day $1, \mathrm{LV}$ $400 \mathrm{mg} / \mathrm{m}^{2}$ day 1 followed by a $46-\mathrm{h} 5$-FU continuous infusion $\left(2400 \mathrm{mg} / \mathrm{m}^{2}\right)$, and irinotecan $100 \mathrm{mg} / \mathrm{m}^{2}$ at day 3 [12]. Induction treatment was administrated every 2 weeks for a maximum of 12 cycles, until disease progression, unacceptable toxicities, surgical intervention, or withdrawal of consent.

Maintenance treatment consisted of bevacizumab $7.5 \mathrm{mg} /$ $\mathrm{kg}$ intravenous infusion over 60 minutes, and capecitabine $1000 \mathrm{mg} / \mathrm{m}^{2}$ day 1 to 14 , every 3 weeks until tumor progression, unacceptable toxicity, or withdrawal of consent.

Dose reductions were required for all grade 3 or 4 toxicities attributed to study medications. Bevacizumab was not dose reduced but delayed or discontinued in patients with grade 3 or 4 toxicities.

\section{Safety and efficacy assessment}

At baseline and before each cycle, clinical and biological examinations were performed. Adverse events were evaluated continuously and graded according to National Cancer Institute Common Toxicity Criteria (NCI CTC) version 3. The response was defined according to $\mathrm{Re}$ sponse Evaluation Criteria In Solid Tumors (RECIST) v1.0. Radiological response assessment was validated in a blinded fashion by an independent radiologist. Tumor responses were assessed every eight weeks by spiral computed tomography. Resectability of metastases was determined by IRFC-multidisciplinary gastrointestinal oncology team before treatment initiation and when the best response was achieved.

\section{Plasma sample collection and analysis}

Blood samples were drawn at baseline and immediately processed for plasma and serum freezing at $-80^{\circ} \mathrm{C}$. Samples frozen more than 4 hours following venous blood collection were not included in the analysis. Enzymelinked immunosorbent assays (ELISA) were used to measure angiopoietin-2 in serum samples and VEGF-A in plasma samples ( $\mathrm{RnD}$ systems) according to the manufacturer's instructions. Each sample was analyzed in duplicate.

\section{Statistical analysis}

The primary endpoint of the trial was to determine the objective response rate to the FOLFIRI3 sans espace bevacizumab regimen in patients with first-line mCRC cancers. The study was designed as an exploratory, pilot, single-arm, multicenter, phase II study. A Simon two-stage (optimal) design was used. At least 11 out of the first 21 patients needed to achieve an objective response in stage 1 for recruitment to continue until a target of 45 fully evaluable patients had been reached. Based on standards available at the time of study design, we considered the standard objective response rate (H0 hypothesis) achieved with FOLFIRI and bevacizumab as $50 \%$. Based on an $\alpha$ and $\beta$ error probabilities of 0.1 respectively, we considered that if an objective response (complete and partial response) was observed in at least 26 out of 45 patients with metastatic colorectal cancers, the regimen would merit further evaluation in prospective subsequent trials. Moreover, regarding the high number of patients who underwent a curative intent surgery, the cohort was extended to 61 patients to include a total of 40 patients with non-resectable disease. Survival data were computed according to Kaplan-Meier method and analyses were performed on an intent-totreat population including all registered patients. Secondary endpoints were PFS, OS, toxicity profile, metastases resection rate, and biologic analysis of possible predictive factors of efficacy and toxicity. PFS was defined as the time from study enrolment to the first documentation of progressive disease (PD) or death from any cause. Overall survival was defined as the time from study enrolment to death from any cause.

\section{Results}

\section{Baseline characteristics}

Sixty-one patients were enrolled in the study between October 2007 and July 2009. The median age of the patients was 63.6 years (range, 38-81). Fifty-seven patients (93\%) had an Eastern Cooperative Oncology Group Performance Status (ECOG PS) 0-1. Thirty-five patients (57\%) presented only one metastatic site and 7 patients (12\%) had 3 or more visceral sites involved by metastases. Twenty-five patients (41\%) had liver-limited metastases. Twenty-two patients (36\%) displayed metachronous metastases at inclusion. Eighteen patients (30\%) had received prior adjuvant chemotherapy, including an oxaliplatin-based chemotherapy for 15 patients (25\% of the whole cohort). Primary tumor was resected in 3 out of the 39 synchronous metastatic patients. Two primary tumor resections were performed before enrolment due to a symptomatic disease and one resection was performed after enrolment due to an occlusion (Table 1).

\section{Administration of FOLFIRI3-bevacizumab}

All patients accomplished at least one cycle of treatment. Patients received a median of 10 cycles of induction chemotherapy (range 2-14) and 40 patients completed all planned cycles of FOLFIRI3-b. Twenty-one patients 
Table 1 Patient's characteristics

\begin{tabular}{|c|c|c|}
\hline \multirow[b]{3}{*}{ Demographic or clinical characteristics } & \multirow{2}{*}{\multicolumn{2}{|c|}{$\begin{array}{c}\text { FOLFIRI3-bevacizumab } \\
(n=61)\end{array}$}} \\
\hline & & \\
\hline & No. of patients & $\%$ \\
\hline Male & 35 & 57 \\
\hline \multicolumn{3}{|l|}{ Age, years } \\
\hline Median & 63.6 & \\
\hline Range & $38-81$ & \\
\hline \multicolumn{3}{|l|}{ ECOG performance status } \\
\hline 0 & 25 & 41 \\
\hline 1 & 32 & 52 \\
\hline 2 & 4 & 7 \\
\hline \multicolumn{3}{|l|}{ Primary tumor type } \\
\hline Colon & 38 & 62 \\
\hline Rectal & 23 & 38 \\
\hline \multicolumn{3}{|l|}{ No. of sites involved by metastases } \\
\hline 1 & 35 & 57 \\
\hline 2 & 19 & 31 \\
\hline$>=3$ & 7 & 12 \\
\hline \multicolumn{3}{|l|}{ Site of metastatic disease } \\
\hline Liver only & 25 & 41 \\
\hline Liver + other & 20 & 33 \\
\hline Other only & 16 & 26 \\
\hline \multicolumn{3}{|l|}{ Prior adjuvant chemotherapy } \\
\hline All & 18 & 30 \\
\hline Oxaliplatin-based & 15 & 25 \\
\hline$<12$ months & 8 & 13 \\
\hline \multicolumn{3}{|l|}{ Synchronous tumors } \\
\hline Yes & 39 & 64 \\
\hline No & 22 & 36 \\
\hline
\end{tabular}

(34\%) discontinued their induction treatment: 6 for progression, 3 for treatment-related toxicities and 12 for programmed metastasis surgery. The relative dose intensity (calculated from FOLFIRI3-b initiation to the last course of chemotherapy delivered before toxicity, disease progression, surgery, or the planned $12^{\text {th }}$ cycle of FOLFIRI3-b) was $88 \%$ for Irinotecan, $85 \%$ for 5 -FU, and $87 \%$ for bevacizumab. Median dose administered for each cycle was $91 \%$ for irinotecan, $95 \%$ for 5 -FU, and $100 \%$ for bevacizumab.

\section{Safety}

Toxicity analysis was performed in the intent-to-treat population (61 patients, Table 2). Twenty patients (33\%) suffered $\geq$ grade III treatment-related side effects. One patient $(1.6 \%)$ died during induction regimen due to treatment-related toxicity (colitis and sepsis). Moreover, one patient with synchronous metastases exhibited a colon cancer bleeding requiring surgery. Post-operative recovery was achieved within 7 days and chemotherapy
Table 2 Grade 3 and 4 adverse events: NCI CTC v.3

\begin{tabular}{|c|c|c|c|c|}
\hline \multirow[b]{3}{*}{ Adverse events } & \multirow{2}{*}{\multicolumn{2}{|c|}{$\begin{array}{c}\begin{array}{c}\text { Induction } \\
\text { chemotherapy }\end{array} \\
(\mathrm{N}=61)\end{array}$}} & \multirow{2}{*}{\multicolumn{2}{|c|}{$\begin{array}{c}\begin{array}{c}\text { Maintenance } \\
\text { chemotherapy }\end{array} \\
(\mathrm{N}=41)\end{array}$}} \\
\hline & & & & \\
\hline & No. of patients & $\%$ & No. of patients & $\%$ \\
\hline Nausea & 1 & 2 & 0 & - \\
\hline Vomiting & 1 & 2 & 0 & - \\
\hline Diarrhea & 9 & 15 & 2 & 5 \\
\hline Mucositis & 0 & - & 0 & - \\
\hline Fatigue & 6 & 10 & 1 & 2 \\
\hline Platelet count decreased & 0 & - & 0 & - \\
\hline Anemia & 0 & - & 0 & - \\
\hline White blood cell decreased & 3 & 5 & 0 & - \\
\hline \multirow[t]{2}{*}{ Neutropenia } & 8 & 13 & 0 & - \\
\hline & (2 grade IV) & & & \\
\hline Febrile neutropenia & 1 & 2 & 0 & - \\
\hline Hypertension & 3 & 5 & 1 & 2 \\
\hline Hemorrhage & 1 & 2 & 0 & - \\
\hline Thromboembolic event & 0 & - & $1^{*}$ & 2 \\
\hline Palmar-plantar syndrome & 0 & - & 6 & 15 \\
\hline
\end{tabular}

*One catheter related deep vein thrombosis.

Grade IV toxicity: the only grade IV toxicity observed was neutropenia.

was reintroduced at day 28 post-surgery. Most common grade III-IV toxicities were diarrhea (15\%), neutropenia (13\%), asthenia (10\%), and infections (4\%). Hypertensionrelated medications needed to be increased in 3 patients.

\section{Efficacy}

Among the 60 assessable patients, ORR was 66.7\% (95\% CI: $55-79$ ) including $58.4 \%$ of partial responses and $8.3 \%$ of complete responses (CR). Stable disease (SD) was observed in $25 \%$ of patients conferring to this strategy a disease control rate of $91.7 \%$. An independent review of the radiological responses was performed and showed only one difference: one patient was considered to be in CR by our investigators and in non-measurable $\mathrm{SD}$ by the independent committee. However, later liver resection confirmed histological CR.

After a median time of follow-up of 46.7 months (data base up-dated in December 2012), 56 patients (92\%) had progressed. The median PFS was 12.72 months (95\% CI: 9-16 months). So far, 42 patients $(68.8 \%)$ have died and median OS was 24.5 months (95\% CI: 10.6-38.3 months). Of note, none of the patient's characteristics influenced the clinical results achieved with FOLFIRI3-bevacizumab treatment. Particularly, the ORR was $58.3 \%$ in patients above 70 year-old compared to $68.8 \%$ for patients less than 70 year old at the inclusion $(\mathrm{p}=0.51)$. Moreover, FOLFIRI3-bevacizumab was also effective in patients treated with oxaliplatin-based adjuvant chemotherapy (ORR of $60 \%, \mathrm{p}=0.54$ ). 


\section{Surgery of metastases}

Twenty-one patients (34\%) underwent curative-intent surgery of their metastases. A complete histological response was observed in 5 patients. R0 resection was achieved in twenty patients, while the resection status was considered as R1 for one patient. Four of these patients were initially considered as non-resectable, including one patient with 2 sites involved by metastases (lung and liver). Five patients (24\%) among the 21 patients who have undergone metastasis surgery were still in complete remission at the time of the last analysis. The median progression free survival was 23.6 months (95\% CI: 17.3-29.9 months) in patients who underwent a surgery of their metastases compared to 9.4 months (95\% CI: 8.47-10.33 months) for patients with non-resected metastases (Figure $1 ; \mathrm{p}<0.001$ ). The median overall survival was not reached in patients who underwent a metastatic surgery, while median OS was 18.33 months (95\% CI: $15.15-21.5$ months) in patients with unresectable disease $(\mathrm{p}<0.001)$.

\section{Feasibility and efficacy of maintenance treatment by capecitabine-bevacizumab}

Twenty patients did not receive maintenance chemotherapy: 1 patient died during induction regimen, 11 patients displayed progressive diseases before capecitabinebevacizumab initiation, 8 patients underwent curativeintent surgery and no further treatment was proposed. Then, capecitabine-bevacizumab therapy was administered to 40 eligible patients and one more patient, who refused capecitabine, received only bevacizumab.

A total of 346 cycles and a median of 8.7 cycles was administered (range 1-33) per patient at the time of analysis. Median dose of capecitabine per cycle and per patient was $83.4 \%$.

The treatment was generally well tolerated. No grade IV toxicity was recorded and $20 \%$ of patients experienced grade III toxicities. Most frequent grade III toxicities were hand-foot syndrome (15\%), and diarrhea (5\%). Bevacizumab had to be stopped before capecitabine in only one case due to catheter-related deep vein thrombosis. Overall, maintenance treatment was discontinued for toxicity or withdrawal of consent in 2 patients (5\%). The median duration of disease control from first cycle of maintenance therapy was 8 months (range, 1-38).

High levels of plasma angiopoietin-2 at baseline correlate with poor clinical outcomes in patients treated with FOLFIRI3-b

In 51 patients, plasma and serum were available at baseline for analysis. Among angiogenic factors, angiopoietin-2 (Ang-2) was recently proposed in a cohort of 34 patients, as a candidate biomarker for outcomes of $\mathrm{mCRC}$ patients treated with bevacizumab-containing chemotherapy [14]. Then, we decided to monitor Ang-2 and VEGF-A levels in this study. Seven patients included in this phase II clinical trial had increased VEGF-A levels compared to normal

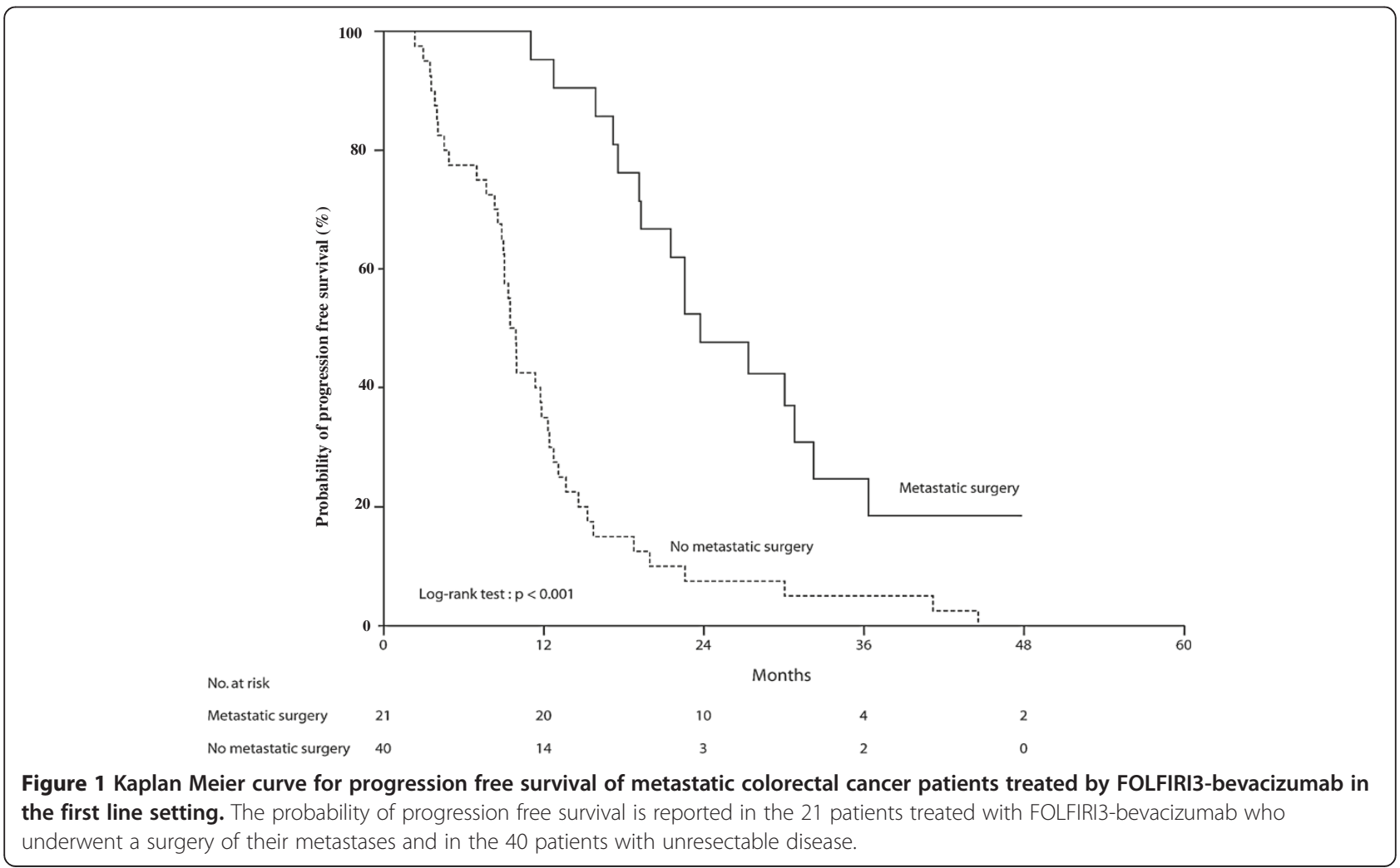


volunteers or stage II-III colorectal cancers. However, we did not observe a significant negative influence of increased VEGF-A levels on the ORR (83\%), PFS (10.7 months) or OS (20.6 months). A preliminary set of experiments confirmed that Ang-2 levels remain below $5 \mathrm{ng} / \mathrm{mL}$ in all normal volunteers $(\mathrm{n}=20)$ or stage II-III colorectal cancers $(n=20)$, in line with the results of Goede et al. [14]. Ang-2 plasma levels above $5 \mathrm{ng} / \mathrm{mL}$ at baseline were observed in nine patients (17.3\%) of our cohort. ORR was $44 \%$ in patients with increased levels of Ang-2, compared to $74.4 \%$ in patients with Ang-2 levels below $5 \mathrm{ng} / \mathrm{mL}$. The median PFS was 7.7 months (95\% CI: 0-15.9 months) in patients with high Ang-2 levels compared with 13.6 months (95\% CI: 10.117.2 months) in patients with Ang-2 levels below $5 \mathrm{ng} / \mathrm{mL}$ (Figure 2A). Furthermore, overall survival was significantly better in patients with low levels of Ang-2 (median OS: 34.7 months; 95\% CI: 19.8-49.7) than in patients with high levels of Ang-2 (median OS: 7.7 months; 95\% CI: 5-16.3 months; Figure 2B). In multivariate analysis, surgery of metastases and Ang-2 levels were the only independent prognostic factors for PFS and OS. Indeed, a level of Ang-2 above $5 \mathrm{ng} / \mathrm{mL}$ was confirmed as an independent prognostic factor for progression free survival $(\mathrm{HR}=0.357 ; 95 \% \mathrm{CI}: 0.168-0.76, \mathrm{p}=0.005)$ and overall survival $(\mathrm{HR}=0.226$; $95 \% \mathrm{CI}$ : 0.098-0.53, $\mathrm{p}=0.0002$ ). Altogether, these results confirm the clinical interest of angiopoietin-2 monitoring to predict PFS and OS in mCRC patients and suggest a decreased efficacy of FOLFIRI3-b in these patients.

\section{Discussion}

Irinotecan inhibits DNA replication by interfering with topoisomerase I. Topoisomerase enzymes display a helicase activity involved in DNA repair. Then, it might be possible that topoisomerase blockage following DNA damage could prevent DNA repair and enhance apoptosis induced by chemotherapy. Indeed, preclinical evidence suggested that the anti-proliferative activity of 5FU and irinotecan combination is schedule dependent [15-18]. In line with the above hypothesis, several studies showed that a delayed administration of irinotecan increases FOLFIRI cytotoxicity. FOLFIRI2 regimen (irinotecan delivery at the end of a modified LV5FU2 chemotherapy) in heavily pretreated CRC patients induced promising objective responses but also a limiting hematologic toxicity [19]. As reported here and in previous studies, FOLFIRI3 has a more appropriate toxicity profile [12]. In addition, bifractionated irinotecan combined to LV5FU2 (FOLFIRI3) was shown to be active in mCRC resistant to FOLFIRI and has been correlated to a longer PFS in second line treatment of mCRC patients [10-12]. However, the clinical interest of this regimen was never investigated in the first-line setting, where the best chemotherapy to combine with bevacizumab is still a matter of debate.

In a pivotal randomized clinical trial, bevacizumab combination with IFL (weekly irinotecan plus bolus 5fluorouracile/leucovorin) improved both median PFS and median OS in previously untreated mCRC patients. Patients receiving both bevacizumab and IFL had a median PFS of 10.6 months and a median OS of 20.3 months,

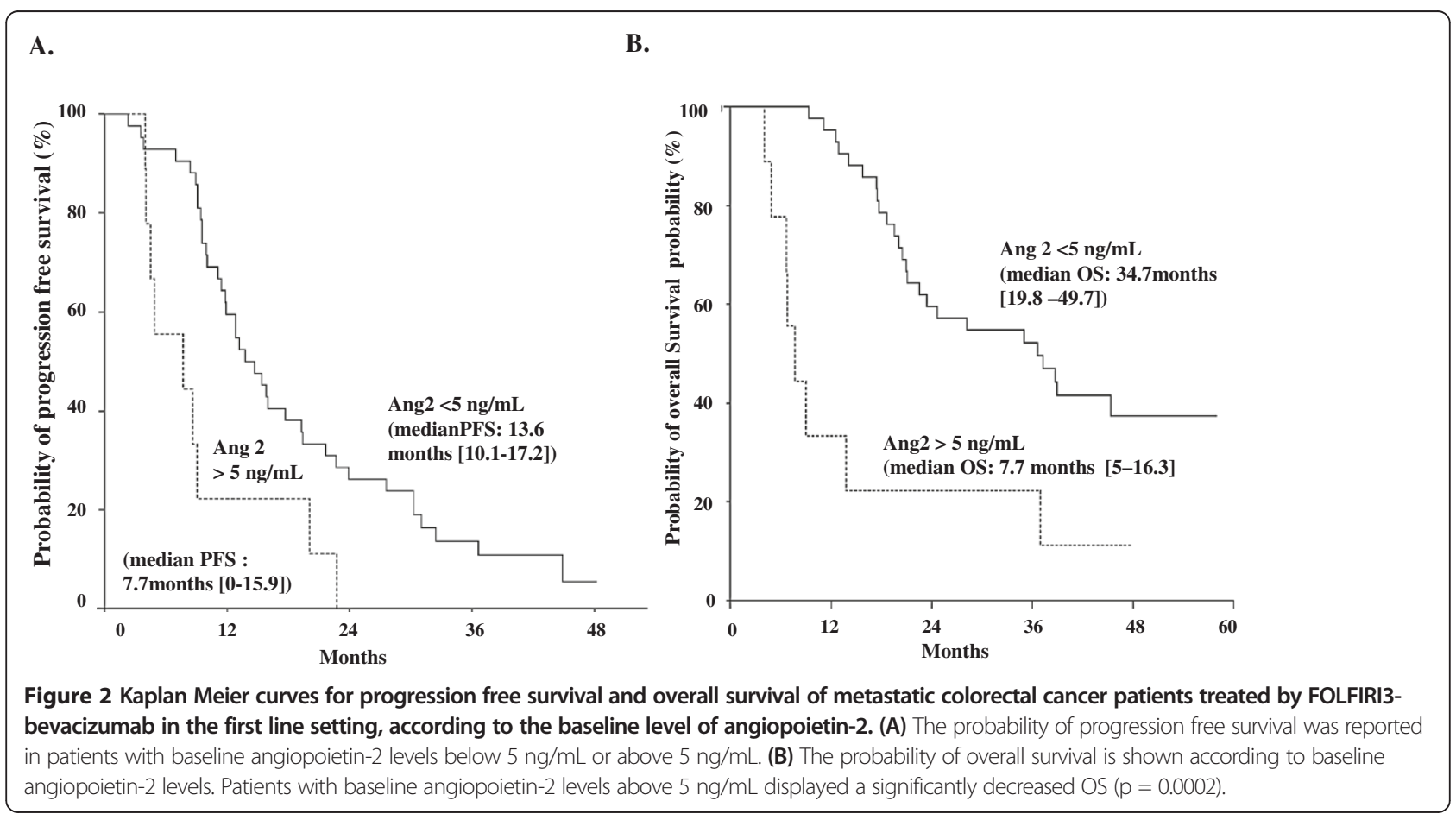


while median PFS and OS were 6.2 and 15.6 months respectively for patients treated with IFL alone [13]. FOLFIRI and bevacizumab efficacy was primarily assessed in retrospective studies. López $\mathrm{R}$ et al. reported a 50.5\% objective response rate, a 10.6 month median PFS and a 20.7 month median OS in first line treatment of mCRC patients [20]. Seventy one percent of these patients had liver metastases and $14 \%$ of them underwent curativeintent surgery. In this study, adverse events were the cause of treatment discontinuation for $8 \%$ of the patients compared to $5 \%$ in our study. In a recently reported phase II trial including 43 patients, FOLFIRI and bevacizumab achieved a $65 \%$ response rate, a 12.8 months median PFS and a median OS of 31.9 months [21]. Adverse events were the cause of treatment discontinuation in 8 patients and curative-intent surgery was performed in 4 patients
[21]. Of note, the addition of bevacizumab to FOLFOX has shown similar results with a response rate of $52 \%$ and a median PFS of 9.9 months [22].

The BICC-C study contributed to clarify the relative interest of three different irinotecan-based chemotherapies in the first line treatment of mCRC. The addition of oral capecitabine to irinotecan (CapeIRI) induced an enhanced level of toxicities. Furthermore, median overall survival was significantly higher for patients treated with FOLFIRIbevacizumab (median OS of 28 months vs 19.2 months for mIFL-treated patients) [23].

In the current study, we found that FOLFIRI3- bevacizumab was a manageable option in first line metastatic colorectal cancer patients. Indeed, side effects and toxic deaths observed in our study are comparable to those reported by other clinical trials. The ratio of adverse

Table 3 Review of the main clinical trials performed in first line metastatic colorectal cancer

\begin{tabular}{|c|c|c|c|c|c|c|c|c|}
\hline & Chemotherapy & $\begin{array}{c}\text { Liver } \\
\text { metastases } \\
\text { only (\%) }\end{array}$ & $\begin{array}{l}\text { One metastatic } \\
\text { site only }(\%)\end{array}$ & ORR (\%) & $\begin{array}{c}\text { mPFS } \\
\text { (months) }\end{array}$ & $\begin{array}{c}\text { mOS } \\
\text { (months) }\end{array}$ & Ref & Comments \\
\hline Tournigand C et al. [9] & FOLFIRI & NR & 56 & 56 & 8.5 & 21.5 & $\begin{array}{l}\text { J Clin Oncol 2004; } \\
\text { 22(2):229-37. }\end{array}$ & \\
\hline Colluci G et al. [34] & FOLFIRI & 50 & 56 & 31 & 7 & 14 & $\begin{array}{l}\text { J Clin Oncol 2005; } \\
\text { 23:4866-4875. }\end{array}$ & \\
\hline Labiancha $R$ et al. [35] & FOLFIRI & NR & NR & 42 & 6 & 18 & $\begin{array}{l}\text { Annals of Oncology } \\
2011 ; 22: 1236-1242 .\end{array}$ & \\
\hline $\begin{array}{c}\text { Koopman M } \\
\text { (CAIRO study) [36] }\end{array}$ & $\begin{array}{l}\text { FOLFOX or } \\
\text { FOLFIRI }\end{array}$ & 23 & NR & 41 & 7,8 & 17.4 & $\begin{array}{l}\text { Lancet 2007; } \\
\text { 370:135-42. }\end{array}$ & \\
\hline $\begin{array}{c}\text { Ducreux M } \\
\text { (FFCD2000-05) [37] }\end{array}$ & FOLFOX & NR & 52 & 58 & 7.6 & 16.2 & $\begin{array}{c}\text { Lancet Oncol 2011; } \\
\text { 12:1032-44. }\end{array}$ & \\
\hline $\begin{array}{c}\text { Chibaudel B } \\
\text { (OPTIMOX2 study) [25] }\end{array}$ & FOLFOX7 & NR & 42 & 59.6 & 8,6 & 23.8 & $\begin{array}{l}\text { J Clin Oncol 2009; } \\
\text { 27:5727-5733. }\end{array}$ & $\begin{array}{l}\text { Maintenance } \\
\text { arm }\end{array}$ \\
\hline $\begin{array}{c}\text { Maughan TS } \\
\text { (COIN study arm 1) [38] }\end{array}$ & FOLFOX & 21 & 35 & 57 & 8,6 & 17.9 & $\begin{array}{c}\text { Lancet 2011; } \\
\text { 377(9783):2103-2114. }\end{array}$ & \\
\hline Hurwitz $\mathrm{H}$ et al. [13] & $\mathrm{IFL}+\mathrm{Bev}$ & NR & 37 & 44.8 & 10.6 & 20.3 & $\begin{array}{l}\text { N Engl J Med 2004; } \\
\text { 350:2335-42. }\end{array}$ & \\
\hline $\begin{array}{c}\text { Fuchs CS } \\
\text { (BICC study) [23] }\end{array}$ & Folfiri-bev & NR & NR & 57.9 & 11.2 & 28 & $\begin{array}{l}\text { J Clin Oncol 2007; } \\
\text { 25:4779-4786. }\end{array}$ & \\
\hline $\begin{array}{c}\text { SALTZ LB } \\
\text { (NO16966) [39] }\end{array}$ & FOLFOX + bev & NR & 43 & & 9.4 & 21.3 & $\begin{array}{l}\text { J Clin Oncol. 2008; } \\
\text { 26(12):2013-9. }\end{array}$ & \\
\hline $\begin{array}{c}\text { Schmoll HJ } \\
\text { (Horizon study) [40] }\end{array}$ & FOLFOX + bev & 22 & 45 & 47 & 10.3 & 22.3 & $\begin{array}{l}\text { J Clin Oncol 2012; } \\
\text { 30:3588-3595. }\end{array}$ & \\
\hline $\begin{array}{c}\text { Van Cutsem } \\
\text { (Crystal study) [41] }\end{array}$ & FOLFIRI cetux & 21,5 & NR & 57,2 & 9.9 & 23.5 & $\begin{array}{l}\text { J Clin Oncol 2011; } \\
\text { 29:2011-2019. }\end{array}$ & Kras wt only \\
\hline $\begin{array}{c}\text { Maughan TS } \\
\text { (COIN study arm 2) [38] }\end{array}$ & FOLFOX cetux & 24 & 37 & 64 & 8.6 & 17 & $\begin{array}{c}\text { Lancet. 2011; } \\
\text { 377(9783):2103-2114. }\end{array}$ & Kras wt only \\
\hline $\begin{array}{c}\text { Douillard JY } \\
\text { (Prime study) [42] }\end{array}$ & $\begin{array}{c}\text { FOLFOX } \\
\text { pamitumumab }\end{array}$ & 18 & 21 & 55 & 9.6 & 23.9 & $\begin{array}{l}\text { J Clin Oncol 2010; } \\
\text { 28:4697-4705. }\end{array}$ & Kras wt only \\
\hline $\begin{array}{c}\text { Bokemeyer } \\
\text { (OPUS study) [43] }\end{array}$ & FOLFOX + cetux & 30 & 44 & 58 & 8.3 & 22.8 & $\begin{array}{l}\text { Annals of Oncology } \\
2011 ; 22: 1535-1546 .\end{array}$ & Kras wt only \\
\hline Masi G [44] & FOLFOXIRI & 34 & 55 & 60 & 9.8 & 23.4 & $\begin{array}{l}\text { J Natl Cancer Inst } \\
\text { 2011;103:21-30. }\end{array}$ & \\
\hline Masi G [30] & FOLFOXIRI beva & 53 & 58 & 77 & 13.1 & 30.9 & $\begin{array}{c}\text { Lancet Oncol 2010; } \\
11: 845-52 .\end{array}$ & \\
\hline
\end{tabular}


events leading to death was $1.6 \%$ in our study compared to $2.6 \%$ and $2 \%$ in the pivotal study reported by Hurwitz et al. and by the BEAT study respectively [13,24].

Moreover, the present trial confirms the feasibility of a maintenance chemotherapy combining capecitabine and bevacizumab following FOLFIRI3-b. Maintenance chemotherapy might be a convenient fashion to extent the period of disease control while minimizing the cumulative side effects [25-28]. Our results indicate that bevacizumab and capecitabine maintenance chemotherapy is feasible after FOLFIRI3-bevacizumab, since no grade IV toxicity occurred and only two patients out of 41 exposed to this strategy, discontinued capecitabine following side effects.

A second conclusion that can be drawn from the current study is that survival achieved in patients treated by FOLFIRI3-b is similar to those reported by previous clinical trials (Table 3). The median PFS and OS observed in patients with unresectable metastases were 9.4 months (95\% CI: 8.47-10.33 months) and 18.33 months (95\% CI: 15.15-21.5 months) respectively. Of note, patients included in the CONcePT trial achieved a median PFS of 12 months [27], while patients included in the MACRO trial and treated with Xelox-bevacizumab followed by bevacizumab alone as a maintenance therapy displayed a median PFS of 9.7 months and a median OS of 20 months [28]. Moreover, we cannot exclude a negative impact of FOLFIRI3-b regimen on patient's quality of life. Indeed FOLFIRI3-b requires the administration of irinotecan twice per cycle (before and at the end of continuous 5FU), extending both length of hospitalization and healthcare travel costs.

Nevertheless, a possible clinical interest of FOLFIRI3-b might be the high level of tumor shrinkage observed in our study. Indeed, the $66.7 \%$ ORR observed in the FOLFIRI3-bevacizumab study may be considered for patients with primary unresectable disease in whom downsizing is mandatory to allow metastasis surgery. The correlation established between the response rate and the resection rate supports chemotherapy optimization in $\mathrm{mCRC}$ patients who might potentially become candidate for surgery [29]. The high ORR observed in our study might reflect a favorable selection of patients as suggested by the ratio of patients with only one site involved by metastases (57\%). A review indicating the ORR, mPFS and mOS achieved in recent clinical trials according to the ratio of patients with only one metastatic site is summarized in Table 3. FOLFIRI3 and bevacizumab combination compares favorably with other regimen.

Promising results have also recently been reported in $57 \mathrm{mCRC}$ patients treated with FOLFOXIRI and bevacizumab. 44 of these patients (77\%) achieved a partial response and $26 \%$ of them underwent a radical surgery of their metastases. FOLFOXIRI-bevacizumab led to a median PFS and an OS of 13.1 and 30.9 months [30]. Then, FOLFIRI3- bevacizumab might be of particular interest in patients previously treated with oxaliplatin-containing adjuvant chemotherapy and not eligible to FOLFOX or FOLFOXIRI regimen, especially if the induction of a tumor shrinkage is require to allow optimal resection of the metastatic disease. Of note, an ORR of $60 \%$ was achieved after FOLFIRI3-b treatment in patients exposed to oxaliplatin.

Finally, our study confirmed the prognostic value of plasma angiopoietin-2 levels in metastatic CRC. This result is of particular interest since most angiogenic related biomarkers might be related to prognosis only when monitored after treatment initiation. Here, a baseline Ang-2 level above $5 \mathrm{ng} / \mathrm{mL}$ was confirmed as an independent prognostic factor for progression free survival $(\mathrm{HR}=$ 0.357; 95\% CI: 0.168-0.76, $\mathrm{p}=0.005)$ and overall survival $(\mathrm{HR}=0.226$; 95\% CI: 0.098-0.53, $\mathrm{p}=0.0002)$.

To our knowledge, angiopoietin-2 monitoring was not reported in randomized clinical trials, precluding any conclusion regarding a potential predictive value of this biomarker.

However, our results are in agreement with the previous report of Goede et al., where high levels of angiopoietin-2 had a prognosis value and correlated with a decreased survival in a cohort of 34 colorectal cancer patients treated by chemotherapy and bevacizumab [14].

Several evidences support the direct role of angiopoietin-2 in cancer prognosis. First, angiopoietin-2 expression was shown to be correlated with colorectal cancer stages and progression [31]. In addition, angiopoietin-2 was identified as an independent prognosis biomarker in myeloid leukemia and melanoma patients not treated with antiangiogenic therapies [32,33].

\section{Conclusion}

In conclusion, front-line therapy with FOLFIRI-3bevacizumab is associated with an acceptable toxicity. A promising objective response rate was achieved, particularly in patients previously exposed to oxaliplatin. However, unfavorable clinical outcomes were observed in patients with high levels of angiopoietin-2.

\section{Competing interests \\ The authors declare that they have no competing interests.}

\section{Authors' contributions}

SK, ED, MJ, TNG, ZL, BH, SF, DC; NL, MD and CB included patients; SK, EC, CB wrote the manuscript; FM and VN performed statistical analysis; $B G$ performed RECIST criteria assessment; MJ, ED performed Angiopoietin monitoring, SK and CB analyzed results. All authors read and approved the final manuscript.

\section{Acknowledgements}

The authors would like to thank Ms Marion Jacquin for manuscript review, the investigators and their team.

\section{Funding}

This work was supported by the Franche Comté regional council. 


\section{Author details}

${ }^{1}$ Department of medical oncology, University Hospital of Besançon, Besançon, France. ${ }^{2}$ Department of digestive and liver surgery, University Hospital of Besançon, Besançon, France. ${ }^{3}$ Department of gastroenterology, Hospital of Belfort-Montbeliard, Montbeliard, France. ${ }^{4}$ Department of gastroenterology, Hospital of Vesoul, Vesoul, France. ${ }^{5}$ Department of surgery, Hospital of Belfort-Montbeliard, Montbeliard, France. ${ }^{6}$ Department of pharmacy, University Hospital of Besançon, Besançon, France. ${ }^{7}$ Department of radiology, University Hospital of Dijon, Dijon, France. ${ }^{8}$ INSERM, University of Franche-Comté, Unit 1098, Besançon, France. ${ }^{9}$ Medical Oncology Unit, J. Minjoz University Teaching Hospital, Boulevard Alexandre Fleming, Besancon F-25000, France.

Received: 24 March 2013 Accepted: 10 December 2013 Published: 27 December 2013

\section{References}

1. Kopetz S, Chang G, Overman M, Eng C, Sargent D, Larson D: Improved Survival in Metastatic Colorectal Cancer Is Associated With Adoption of Hepatic Resection and Improved Chemotherapy. J Clin Oncol 2009, 27:3677-3683

2. André T, Boni C, Navarro M, Tabernero J, Hickish T, et al: Improved Overall Survival With Oxaliplatin, Fluorouracil, and Leucovorin As Adjuvant Treatment in Stage II or III Colon Cancer in the MOSAIC. J Clin Oncol 2009, 27:3109-3116.

3. Kuebler JP, Wieand HS, O'Connell MJ, Smith RE, Colangelo LH, et al: Oxaliplatin Combined With Weekly Bolus Fluorouracil and Leucovorin As Surgical Adjuvant Chemotherapy for Stage II and III Colon Cancer: Results From NSABP C-07. J Clin Oncol 2007, 25:2198-2204.

4. Douillard JY, Cunningham D, Roth $A D$, Navarro M, James RD, et al: Irinotecan combined with fluorouracil compared with fluorouracil alone as first-line treatment for metastatic colorectal cancer: a multicentre randomised trial. Lancet 2000, 355:1041-1047.

5. Saltz LB, Cox JP, Blanke C, Rosen L, Fehrenbacher $L$, et al: Irinotecan plus fluorouracil and leucovorin for metastatic colorectal cancer. Irinotecan Study Group. N Engl J Med 2000, 343:905.

6. Cunningham D, Pyrhönen S, James RD, Punt CJ, Hickish TF, et al: Randomised trial of irinotecan plus supportive care versus supportive care alone after fluorouracil failure for patients with metastatic colorectal cancer. Lancet 1998, 352:1413-1418.

7. Rougier P, Van Cutsem E, Bajetta E, Niederle N, Possinger K, et al: Randomised trial of irinotecan versus fluorouracil by continuous infusion after fluorouracil failure in patients with metastatic colorectal cancer. Lancet 1998, 352:1407-1412.

8. Sobrero AF, Maurel J, Fehrenbacher L, Scheithauer W, Abubakr YA, et al: EPIC: phase III trial of cetuximab plus irinotecan after fluoropyrimidine and oxaliplatin failure in patients with metastatic colorectal cancer. J Clin Oncol 2008, 26:2311-2319.

9. Tournigand C, Andre T, Achille E, et al: FOLFIRI followed by FOLFOX6 or the reverse sequence in advanced colorectal cancer: A randomized GERCOR Study. J Clin Oncol 2004, 22:229.

10. Mabro M, Artru P, André T, Flesch M, Maindrault-Goebel F, et al: A phase II study of FOLFIRI-3 (double infusion of irinotecan combined with LV5FU) after FOLFOX in advanced colorectal cancer patients. Br J Cancer 2006 94:1287-1292

11. Bidard FC, Tournigand C, André T, Mabro M, Figer A, et al: Efficacy of FOLFIRI-3 (irinotecan D1, D3 combined with LV5-FU) or other irinotecanbased regimens in oxaliplatin-pretreated metastatic colorectal cancer in the GERCOR OPTIMOX1 study. Ann Oncol 2009, 20:1042-1047.

12. Viel E, Demarchi MF, Chaigneau L, Nguyen T, Legat C, Stein U, et al: A retrospective study of bifractionated CPT-11 with LF5FU infusion (FOLFIRI-3) in colorectal cancer patients pretreated with oxaliplatin and CPT-11 containing chemotherapies. Am J Clin Oncol 2008, 31:89-94.

13. Hurwitz H, Fehrenbacher L, Novotny W, Cartwright T, Hainsworth J, et al: Bevacizumab plus irinotecan, fluorouracil, and leucovorin for metastatic colorectal cancer. N Engl J Med 2004, 350:2335-2342.

14. Goede V, Coutelle O, Neuneier J, Reinacher-Schick A, Schnell R, et al: Identification of serum angiopoietin-2 as a biomarker for clinical outcome of colorectal cancer patients treated with bevacizumabcontaining therapy. Br J Cancer 2010, 103:1407-1414.
15. Jaxel C, Kohn KW, Wani MC, et al: Structure-activity study of the actions of camptothecin derivatives on mammalian topoisomerase I: evidence for a specific receptor site and a relation to antitumor activity. Cancer Res 1989, 49:1465-1469.

16. Guichard S, Cussac D, Hennebelle l, et al: Sequence dependent activity of the irinotecan-5FU combination in human colon-cancer model HT-29 in vitro and in vivo. Int J Cancer 1997, 73:729-734

17. Guichard S, Hennebelle I, Bugat R, et al: Cellular interaction of 5-fluorouracil and the camptothecin analogue CPT-11 (irinotecan) in human colorectal carcinoma cell line. Biochem Pharmacol 1998, 55:667-676.

18. Mans DRA, Grivicich I, Peters GJ, et al: Sequence dependent growth inhibition and DNA damage formation by the irinotecan-5fluorouracil combination in human colon carcinoma cell lines. Eur J Cancer 1999, 13:1851-1861.

19. Mabro M, Louvet C, Andre T, et al: Bimonthly leucovorin, infusion 5-fluorouracil, hydroxyurea, and irinotecan (FOLFIRI-2) for pretreated metastatic colorectal cancer. Am J Clin Oncol 2003, 26:254-258.

20. López R, Salgado M, Reboredo M, Grande C, Méndez JC, et al: A retrospective observational study on the safety and efficacy of first-line treatment with bevacizumab combined with FOLFIRI in metastatic colorectal cancer. Br J Cancer 2010, 103:1536-1541.

21. Kopetz S, Hoff PM, Morris JS, Wolff RA, Eng C, Glover KY, et al: Phase II trial of infusional fluorouracil, irinotecan, and bevacizumab for metastatic colorectal cancer: efficacy and circulating angiogenic biomarkers associated with therapeutic resistance. J Clin Oncol 2010, 28:453-459.

22. Hochster HS: Bevacizumab in combination with chemotherapy: first-line treatment of patients with metastatic colorectal cancer. Semin Oncol 2006, 33:58-14.

23. Fuchs CS, Marshall J, Mitchell E, et al: Randomized, controlled trial of irinotecan plus infusional, bolus, or oral fluoropyrimidines in first-line treatment of metastatic colorectal cancer: results from the BICC-C Study. J Clin Oncol 2007, 25:4779-4786.

24. Van Cutsem E, Rivera F, Berry S, Kretzschmar A, Michael M, et al: Safety and efficacy of first-line bevacizumab with FOLFOX, XELOX, FOLFIRI and fluoropyrimidines in metastatic colorectal cancer: the BEAT study. Ann Oncol 2009, 20:1842-1847.

25. Chibaudel B, Maindrault-Goebel F, Lledo, Mineur L, André T, et al: Can chemotherapy be discontinued in unresectable metastatic colorectal cancer? The GERCOR OPTIMOX2 Study. J Clin Oncol 2009, 27:5727-5733.

26. Adams R, Meade A, Seymour M, Wilson R, Madi A, et al: Intermittent versus continuous oxaliplatin and fluoropyrimidine combination chemotherapy for fi rst-line treatment of advanced colorectal cancer: results of the randomised phase 3 MRC COIN trial. Lancet Oncol 2011, 12:542-553.

27. Grothey A, Hart L, Rowland K, Ansari R, Alberts S: Intermittent oxaliplatin (oxali) administration and time-to-treatment-failure (TTF) in metastatic colorectal cancer (mCRC): Final results of the phase III CONcePT trial. J Clin Oncol 2008. (Meeting Abstracts); 26, No 15S.

28. Díaz-Rubio E, Gómez-España A, Massutí B, Sastre J, Abad A: First-Line XELOX Plus Bevacizumab Followed by XELOX Plus Bevacizumab or Single-Agent Bevacizumab as Maintenance Therapy in Patients with Metastatic Colorectal Cancer: The Phase III MACRO TTD Study. Oncologist 2012, 17:15-25.

29. Folprecht G, Grothey A, Alberts S, Raab HR, Köhne CH: Neoadjuvant treatment of unresectable colorectal liver metastases: correlation between tumour response and resection rates. Ann Oncol 2005, 16:1311-1319.

30. Masi G, Loupakis F, Salvatore L, Fornaro L, Cremolini C, et al: Bevacizumab with FOLFOXIRI (irinotecan, oxaliplatin, fluorouracil, and folinate) as first-line treatment for metastatic colorectal cancer: a phase 2 trial. Lancet Oncol 2010, 11:845-852.

31. Volkova E, Willis JA, Wells JE, Robinson BA, Dachs GU, Currie MJ: Association of angiopoietin-2, C-reactive protein and markers of obesity and insulin resistance with survival outcome in colorectal cancer. Br J Cancer 2011, 104:51-59.

32. Schliemann $C$, Bieker $R$, Thoennissen $N$, et al: Circulating angiopoietin-2 is a strong prognostic factor in acute myeloid leukemia. Leukemia 2007, 21:1901-1906.

33. Helfrich I, Edler L, Sucker A, et al: Angiopoietin-2 levels are associated with disease progression in metastatic malignant melanoma. Clin Cancer Res 2009, 15:1384-1392.

34. Colucci G, Gebbia V, Paoletti G, Giuliani F, Caruso M, et al: Phase III RANDOMIZED Trial of FOLFIRI Versus FOLFOX4 in the Treatment of 
Advanced Colorectal Cancer: A Multicenter Study of the Gruppo Oncologico Dell'Italia Meridionale. J Clin Oncol 2005, 23:4866-4875.

35. Labianca R, Sobrero A, Isa L, Cortesi E, Barni S, et al: Intermittent versus continuous chemotherapy in advanced colorectal cancer: a randomised 'GISCAD' trial. Annals Oncol 2011, 22:1236-1242.

36. Koopman M, Antonini NF, Dourma J, Wals J, Honkoop A, et al: Sequential versus combination chemotherapy with capecitabine, irinotecan, and oxaliplatin in advanced colorectal cancer (CAIRO): a phase III randomised controlled trial. Lancet 2007, 370:135-142.

37. Dureux M, Malka D, Mendiboure J, Etienne P-L, Texereau P, et al: Sequential versus combination chemotherapy for the treatment of advanced colorectal cancer (FFCD 2000-05): an open-label, randomised, phase 3 trial. Lancet Oncology 2011, 12:1032-1044.

38. Maughan TS, Adams RA, Smith CG, Meade AM, Seymour MT, et al: Addition of cetuximab to oxaliplatin-based first-line combination chemotherapy for treatment of advanced colorectal cancer: results of the randomised phase 3 MRC COIN trial. Lancet 2011, 377:2103-2114.

39. Saltz LB, Clarke S, Dias-Rubio E, Scheithauer W, Figer A, et al: Bevacizumab in combination with oxaliplatin-based chemotherapy as first-line therapy in metastatic colorectal cancer: a randomized phase III study. J Clin Oncol 2008, 26:2013-2019.

40. Schmoll H-J, Cunningham D, Sobrero A, Karapetis CS, Rougier P, et al: Cediranib with mFOLFOX6 versus bevacizumab with mFOLFOX6 as first-line treatment for patients with advanced colorectal cancer: A double-blind, randomized phase III study (HORIZON III). J Clin Oncol 2012, 30:3588-3595.

41. Van Cutsem E, Köhne C-H, Hitre E, Zaluski J, Chang Chien C-R, et al: Cetuximab and chemotherapy as initial treatment for metastatic colorectal cancer. N Engl J Med 2009, 360:1408-1417.

42. Douillard JY, Siena S, Cassidy J, Tabernero J, Burkes R, et al: Randomized, phase III trial of panitumumab with infusional fluorouracil, leucovorin, and oxaliplatin (FOLFOX4) versus FOLFOX4 alone as first-line treatment in patients with previously untreated metastatic colorectal cancer: the prime study. J Clin Oncol 2010, 28:4697-4705.

43. Bokemeyer C, Bondarenko I, Hartmann JT, de Braud F, Schuch G, et al: Efficacy according to biomarker status of cetuximab plus FOLFOX-4 as first-line treatment for metastatic colorectal cancer: the OPUS study. Annals Oncol 2011, 22:1535-1546.

44. Masi G, Vasile E, Loupakis F, Cupini S, Fornaro L, et al: Randomized trial of two induction chemotherapy regimens in metastatic colorectal cancer: an updated analysis. JNCl 2011, 103:21-30.

doi:10.1186/1471-2407-13-611

Cite this article as: Kim et al:: Bifractionated CPT-11 with LV5FU2 infusion (FOLFIRI-3) in combination with bevacizumab: clinical outcomes in first-line metastatic colorectal cancers according to plasma angiopoietin-2 levels. BMC Cancer 2013 13:611.

\section{Submit your next manuscript to BioMed Central and take full advantage of:}

- Convenient online submission

- Thorough peer review

- No space constraints or color figure charges

- Immediate publication on acceptance

- Inclusion in PubMed, CAS, Scopus and Google Scholar

- Research which is freely available for redistribution 